\title{
The Comparative Genius of Leonardo da Vinci and R. Buckminster Fuller
}

\author{
JOHN LANGE \\ California Polytechnic State University \\ USA
}

\begin{abstract}
Without question Leonardo da Vinci has been recognized as the Renaissance genius of the fifteenth century due to the various inventions and structures he designed during his lifetime. The twentieth century is rapidly reaching its conclusion and it appears that the outstanding inventor of this time period has been R. Buckminster Fuller due to his inventions in geodesic domes and tensegrity structures. The author wishes to compare the philosophical and intellectual inventions of these two creative giants and arrive at conclusions based upon their methods of creativity, problem solving and the similarity of their physical or mechanical explorations.
\end{abstract}

\section{INTRODUCTION}

Both men explored the nature of the universe by beginning with elementary geometry. Leonardo da Vinci studied the development of lunes in the Codex Atlanticus, which is similar to Fuller's studies of Synergetic-energetic geometry in his Dymaxion World of Buckminster Fuller. These basic studies in geometry laid the basis for Leonardo's further study in mechanics and structures. Leonardo eventually developed his studies of geometry into such machines as the aerial screw or helicopter and structures used for the centering of arches in the Codex Atlanticus, folio 200, and also a fuselage for a flying machine, M.S.V. 74. These developments by Leonardo da Vinci had no previous anticipation in the fifteenth century.

During the twentieth century R. Buckminster Fuller's studies of synergetic-energetic geometry led to the invention of the Dymaxion automobile, construction of the Geodesic dome which was to be transported by modern day helicopter to remote location for installation and the construction of the Dymaxion Tubular Rowing Shell in 1947. All of these inventions by Fuller were of a mechanical or architectural nature to assist man in his survival on the planet earth.

The psychological, physiological and general background of these two intellectual creators also appears to have a similar basis of comparison. Each man's childhood and developmental patterns seem to be based upon growth from an initial hardship which they overcame in later life. Leonardo da Vinci was the son of Ser Piero da Vinci, a notary who first abandoned his son and then later apprenticed him as an artisan. R. Buckminster Fuller failed to graduate from Harvard contrary to generations of his ancestors and began his career as a mechanic in the United States Navy.

Their use or common development of mapping systems will be explored by the author in relationship to Leonardo's studies for the hydraulics and nautical engineering in Codex Atlanticus, folio $214 \mathrm{Vd}$. and Fuller's similar development of a Floating Breakwater, 1979 U.S. patent 4,136,994. Both of these inventors explored the use of waterway systems and control devices on a major scale; Leonardo da Vinci for the Arno and Mugnone rivers and Fuller introduced the first geodetic Dymaxion Map which would map true distances across the oceans of the world.

This paper will demonstrate the many interconnections between the mechanical devices, architectural structures and philosophical attitudes of these two giants of technological invention. On a personal note, the reassessment of $R$. Buckminster Fuller's work is important to the author because of his connection to Fuller at the University of Pennsylvania where Fuller was a "World Scholar" who influenced a generation of technological exploration.

\section{BACKGROUND}

Modern use of the space frame, modular bathroom, integrated mechanical devices, and much of our satellite and communication structures are based upon Fuller's initial exploration. His studies such as those in topological systems consisting of lines, vertexes and facets have proven fruitful in modern chemistry and mathematics. The "Bucky Ball" or pure carbon was recently discovered as has been predicted by his insights. Therefore, it is important that we review the work of both Leonardo da Vinci and R. Buckminster Fuller to appreciate both the logic of their minds and find possible new avenues for exploration in structural technology in the rapidly approaching twenty-first century.

Leonardo da Vinci's exploration of spatial geometry is documented by his many studies of intersecting circles on 
flat surfaces. The subdivision of the circle by its own radial system is evident in his studies of lunes as well as his drawings of "Geometrical figures and designs for allegorical representations of Truth and Falsehood, Windsor, R.L. 127 oov. In the later studies Leonardo stated that "Fire stands for truth because it destroys all sophistry and falsehood and the mask is for deceitfulness and falsehood-concealer of truth."' By this statement, Leonardo tried to search for the basic elementary units of nature, the stacking of spheres, and to strip away the unnecessary and overlying elements of the composition of the universe and to describe the fact that the earth was round and not only a part of linear Euclidean space as fifteenth century mathematics proposed. By drawing

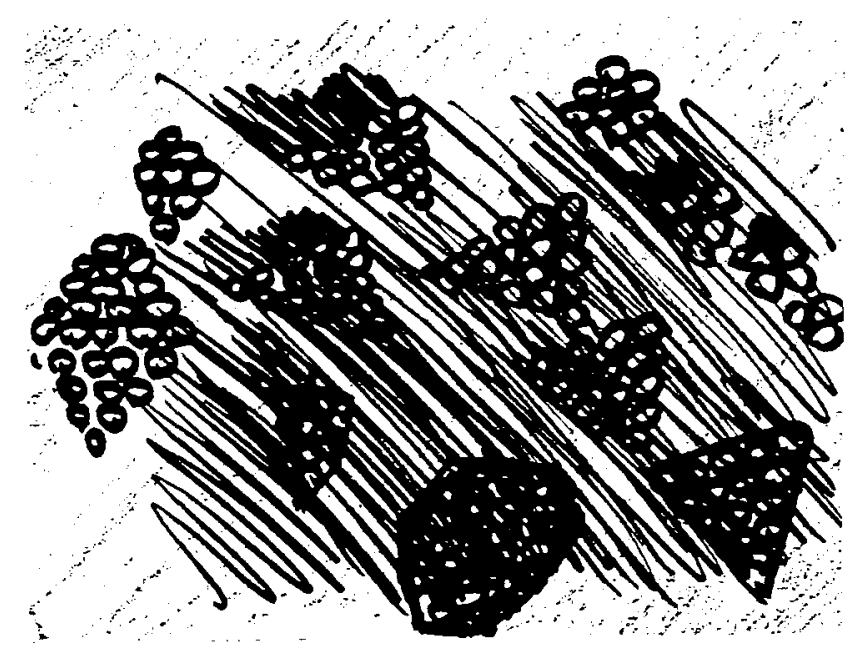

Fig. 1. Stacking patterns, R. Buckminster Fuller.

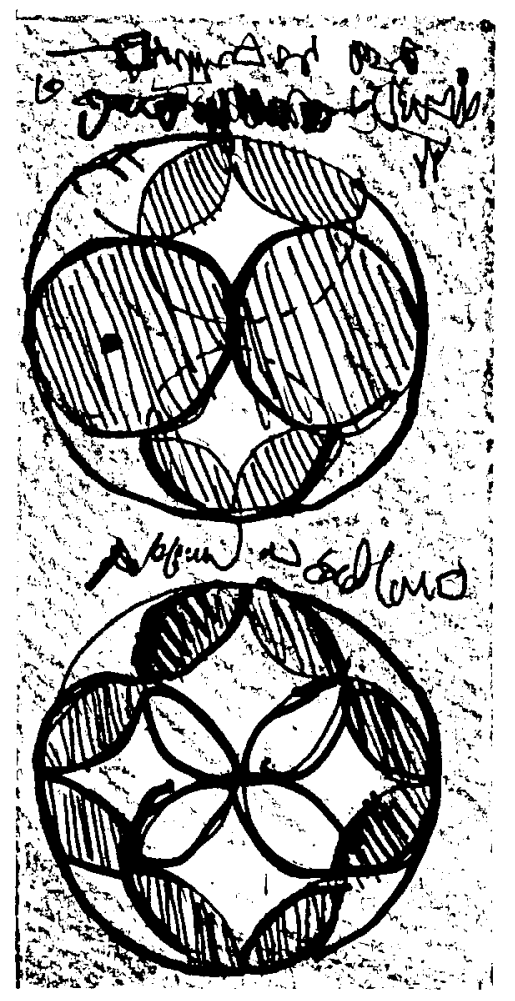

Fig. 2. Lune Studies, Leonardo da Vinci. various combinations of circular form and linear motion Leonardo was attempting to find the underlying nature of all things organic and inorganic. This search was begun by Leonardo long before the advent of chemistry to determine the invisible forces of nature.

From these basic studies of radial geometry Leonardo was able to sketch such inventions as structural arches and vaults that could be constructed of straight line timbers and other wood members rotated in space. It is interesting to note that Leonardo also dealt with the subdivision of light and shade in arched objects. (M.S.B.N. 2038 141). In these drawings there are radial perspective lines that are similar in character to the linear timber members and force lines in the drawing of arches.

By his drawing Leonardo was the first to document that perhaps the force lines generated by circular motion in lunes and structures were similar to the structure of light rays. Einstein's theory of relativity of all matter, whether it be by gravitational, chemical or electrical measurement was predicted by Leonardo's simple drawings. Leonardo used one means to measure all forces of nature, the 'drawing' and its rules of circular and linear geometry. In modern times the computer is approaching this ability. Form $\mathrm{Z}$ and several other visual programs are allowing designers to construct objects with wire frame and other means of analysis that approach the system of constructing drawings that Leonardo used in his explorations in the fifteenth century.

R. Buckminster Fuller's studies of geometry began with the triangle and the tetrahedron which were then generated into the geodesic dome. The triangular use of equal size members was used by Fuller to construct domes of plywood, steel and plastic. The three-dimensional rotation of Leonardo's vaulting studies would produce a structure in many respects similar to Fuller's modern domes. The photographs of Fuller's studies of spheres and domes almost exactly duplicates the visual imagery of Leonardo's studies of arches.

Fuller defined structures that were based upon tetrahedrons, but with some members in compression and others in

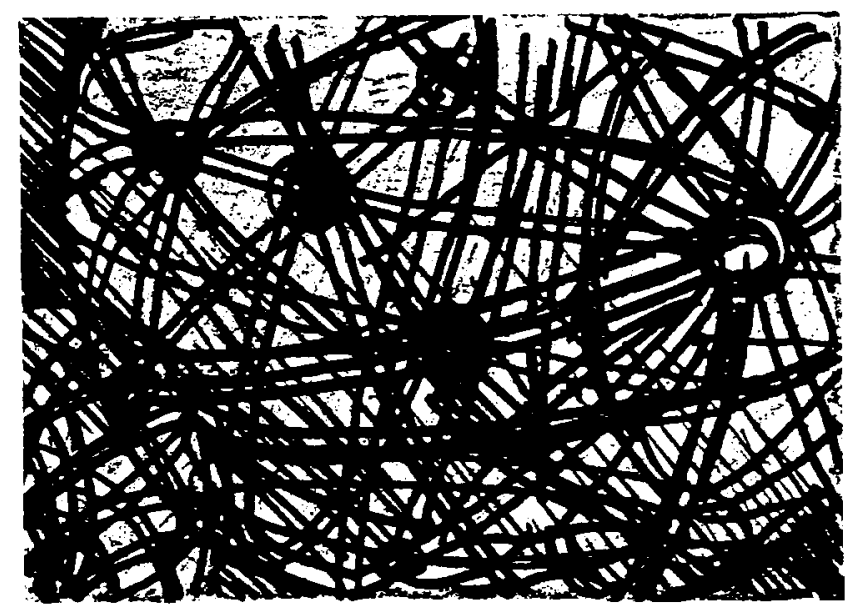

Fig. 3. Geoscope patterns, R. Buckminster Fuller. 


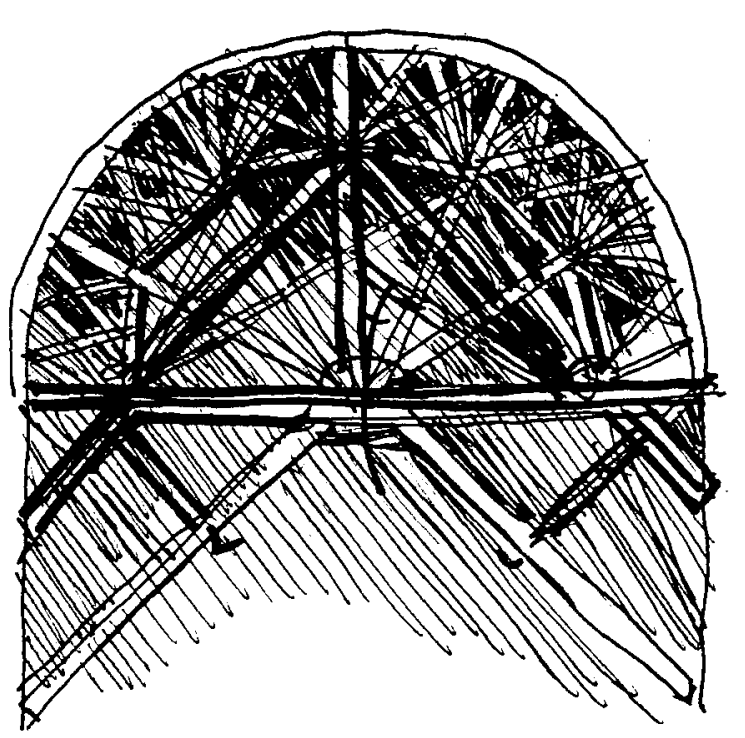

Fig. 4. Arch Studies, Leonardo da Vinci.

tension. The tension members of Fuller's designs utilized the tensile capacity of steel of extremely high grade and quality. The tension members almost became connecting lines in the compositional form which delineated solid compression members and dynamic tension connections. Both Fuller and Leonardo studied the motion of planets as a series of solid joints and dynamic linear gravitational flight patterns. Their structures represented their understanding of the universe at all scales as the representation of dynamic compression elements or spheres held in check by tension orbits.

Fuller designed two houses of notable structural clarity; the Dymaxion 4-D House in Chicago, Illinois, in 1927 and the Fuller House in Wichita, Kansas. Both of these structures contained a central mechanical mast and a light weight steel skin. The Dymaxion House was composed of a hexagonal floor plan and was supported on its exterior by diagonal tension cables. This particular house compares remarkably to Leonardo's original design for a helicopter from Codex Atlanticus, folio 200, in which Leonardo used the same idea of central structural shaft and a covering of lightweight material. In fact Fuller's Dymaxion House was to be delivered on site by a modern day helicopter. Thus Fuller not only generated a modern house form that was similar to Leonardo's early helicopter in its basic structural concept, but also utilized the helicopter's modern day prototype to deliver his own unique invention of modular house.

The Fuller House of Wichita, Kansas is the prototype of a building that Fuller developed from grain storage units. The D.D.U. (Dymaxion Dwelling Unit) or the simpler prototype was used for radar shacks on the Persian Gulf. Most of Fuller's inventions were actually utilized by the military rather than the uninformed general public, for which most of Fuller's inventions were meant, but were too radical in appearance. As Leonardo before, Fuller realized that the fire of war (truth) often displaced the traditional mask. In fact Fuller's House for Wichita, Kansas, was almost a replicant of Leonardo's armored cars, London, British Museum 1860.

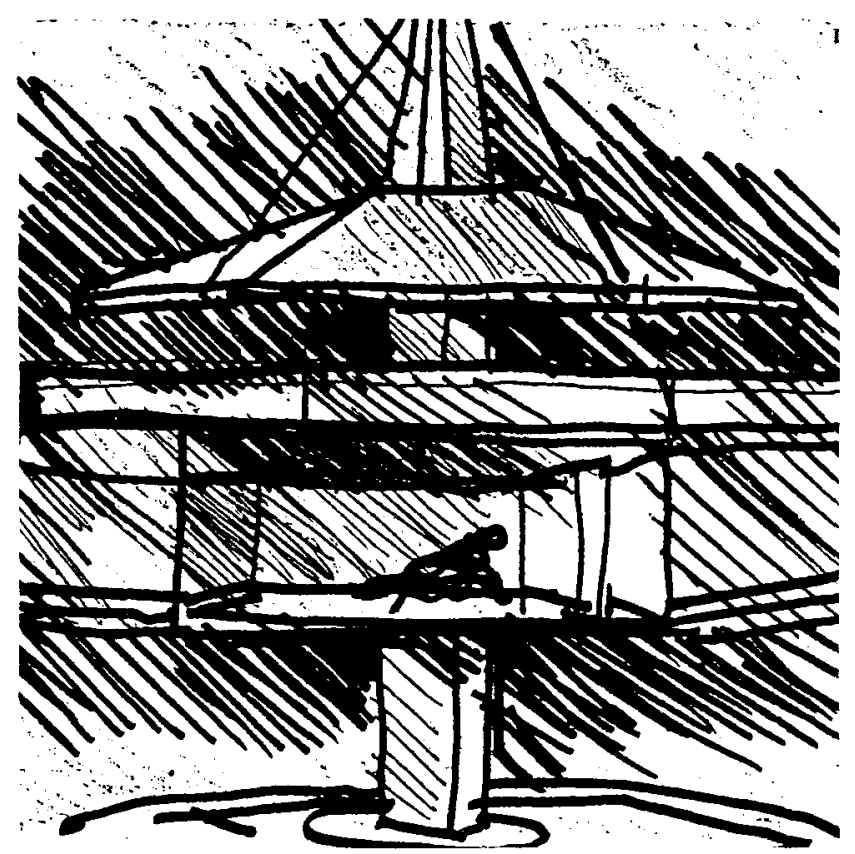

Fig. 5. Dymaxion 4-D House, Chicago, R. Buckminster Fuller.

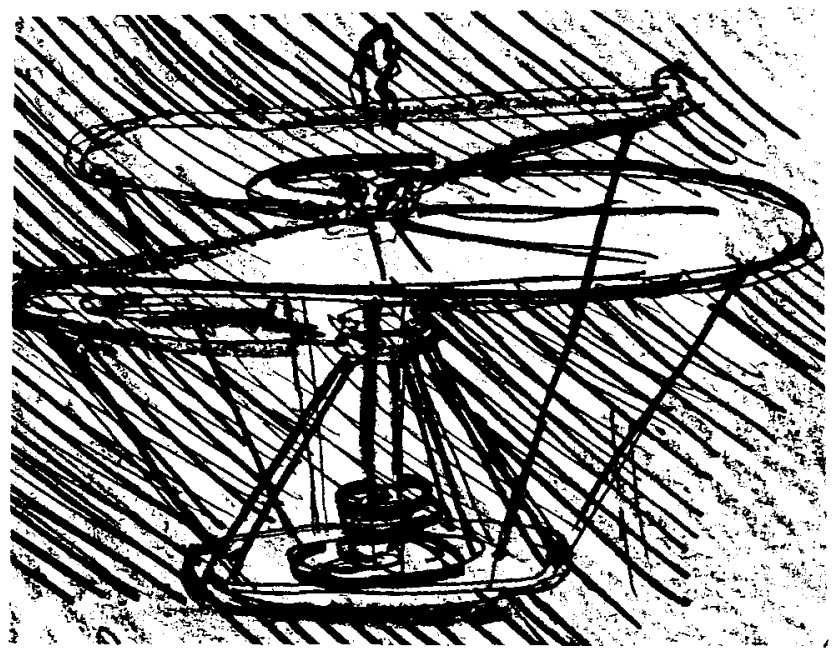

Fig. 6. Helicopter, Leonardo da Vinci.

6-16-19. In these structures Leonardo indicated "I will make covered vehicles, safe and unassailable, which will penetrate the enemy and their artillery..."2 Fuller stated about his prototype housing structures for commercial, residential and military use,

It is for all the foregoing reasons of complete detour of geographically concentrated negative inertias, reflexes, codes and mores that I myself started in 1927 to undertake the then seemingly preposterous air-delivery of entirely tool skill designed and tool-skill fabricated large buildings to remote parts of earth to be spontaneously installable and openable by entirely unskilled peoples within the extraordinarily critical time limits of predictably favorable conditions in the otherwise hostile frontiers. ${ }^{3}$

Therefore both inventive geniuses designed highly practical 
shell structures that were generally put to military use both as portable structures and as secure means of troop deployment. Even in modern day technology the science and military grants usually are available to inventors long before that of free enterprise which only uses those devices which are tested for commercial use and widely accepted by the general population.

Leonardo was apprenticed as an artisan by his father Ser Piero da Vinci to Verrocchio's studio, and according to accounts he painted the head of the angel in his teacher's Baptism of Christ, "painted it so movingly, so expertly, that legend has claimed that Verrocchio straightway laid down his own brush and thereafter devoted himself to other forms of art." ${ }^{4}$ Thus Leonardo did not receive any formal academic training, but began his career as a craftsman. The lack of education that Leonardo did not receive forced him to become self taught and explore concepts and ideas on his own through his own drawings and models.

Fuller as previously stated developed his own education through the navy and his own experimental career. Although he did not graduate from Harvard as his ancestors did; he ultimately received many honorary doctoral degrees from various universities throughout the United States. Both men suffered traumatic emotional experiences within their lifetimes, which caused them to turn inward to develop security through their own identities. Leonardo had many traveling companions during his lifetime, never developing a permanent relationship. Messer Francesco da Melzo being the one who finally inherited Leonardo's drawings and notebooks. Fuller lost a child which caused him to devote his life to his work and his constant companion his wife Anne Hewlett Fuller for over sixty years. After the loss of his daughter and his business venture, Fuller did not speak for one year, instead contemplated his own theories.

There is evidence that links the stature of both Leonardo who was historically noted for his great hand strength, visual ability and radical thinking and Fuller. The tales of Leonardo's physical ability and grace are trumpeted by various historical authors. For example, Pamela Taylor states

His was no great mind meanly housed. He was, on the contrary, exceedingly handsome, with noteworthy eyebrows and a long, beautifully cared for beard, a sumptuous taste, and an original flair in dress, fastidious, a beguiling conversationalist, and surprisingly, hands so strong that they could perform feats which were to become part of his legend. ${ }^{5}$

Fuller also always wanted maximum strength and maximum lightness in his structures. At parties he would question people on how much they thought their houses weighed. This strange question was an indication of his concern with the maximum efficiency of structure in relationship to weight versus size.

William Sheldon, earlier this century, developed a thesis at Columbia University and later through military grants, indicating that high perceptual thinkers were generally low body fat mesomorphs who were artisans by nature. When Sheldon classified forty-six thousand males in the military services into eighty-eight sub-categories by a three dimensional system that described width as mesomorphy, thickness as endomorphy and length as ectomorphy, he allowed mankind the first classification in a comprehensive manner of physique. According to his classification system, Fuller at $5^{\prime}-8$ " and approximately 180 pounds would be a 2,5-1/2,3$1 / 2$ or a person extremely low on body fat or endomorphy (2),

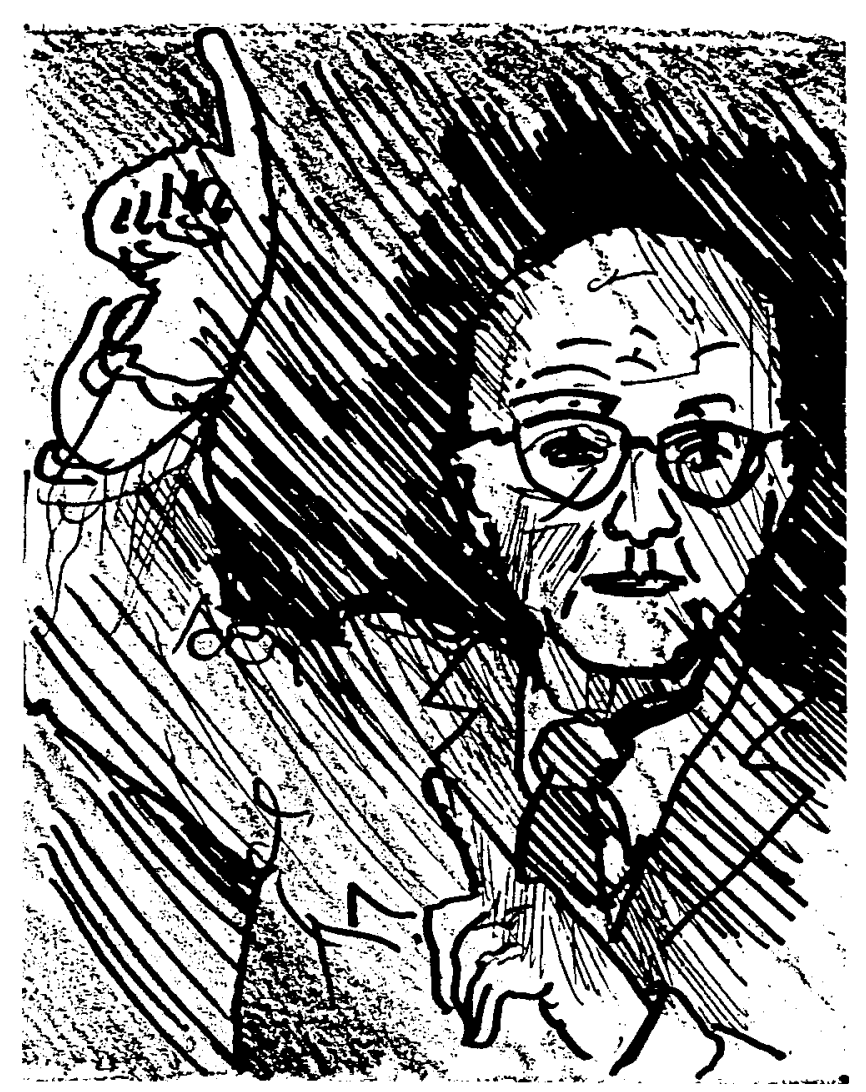

Fig. 7. Richard Buckminster Fuller.

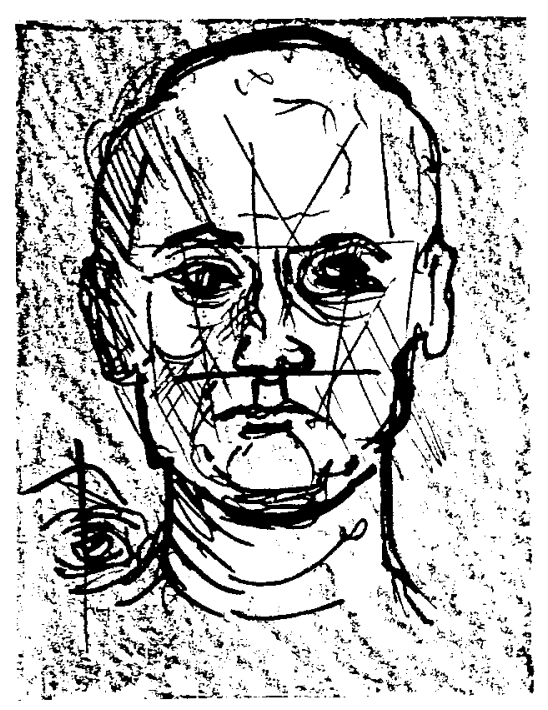

Fig. 8. Self Portrait, Leonardo da Vinci. 
extremely high on mesomorphy (5-1/2), and average on length or ectomorphy (3-1/2). Psychologically he was the equivalent to somebody extremely high in perception and low in feeling or sociability, but extremely high in thinking focused on the present object at hand.

The author would argue that Leonardo da Vinci and R. Buckminster Fuller were in fact both, according to Sheldon's classifications $2,5-1 / 2,3-1 / 2$. This would mean that physically they were proportionally identical. If one examines the photograph of R. Buckminster Fuller and the frontal selfportrait of Leonardo, the match is almost identical in terms of proportion, of nose shape, hairline, ears and mouth structure. It is highly probable that these two men of genius were one in the same in a physical and intellectual or emotional sense.

Leonardo stated,

Measure on yourself the proportion of the composition of your limbs, and if you find any discordant part, take note of it and make very sure that you do not adopt it in the figures that are composed by you, because it is a common vice of painters to take delight in making things similar to themselves. ${ }^{6}$

By this statement Leonardo acknowledged that all of man's creations normally follow the physical proportions of the creator. An object that is massive and light will follow the proportions of its creator. At least in Fuller's Dymaxion structures this concept is very apparent. Just as the Greek architects' statues were highly mesomorphic so were the temples that they designed on the Acropolis. Likewise, Fuller's Dymaxion 4-D house in Chicago and Wichita house were massive solid structures that were really assembled of very lightweight structures and surface skins: maximum brawn with minimum weight. The proportions of Leonardo's helix screw or helicopter closely resemble the proportions of Fuller's Dymaxion house.

Fuller's Dymaxion Map of the world attempted to overcome some of the inherent difficulties in the normal orthographic projection of the world atlas onto a flat surface or page. Fuller lessened this problem by inventing a Dymaxion map which was in effect a flattened geodesic dome upon which a more accurate transition could be made in measurement from a sphere to a flat plane. Fuller developed such a map because of his interest in engineering and the practical necessity of such a device's importance gained through his early years experience in the navy. The basic engineering requirement to transport his invented products to a worldwide public or clientele drove him to use the same basic understanding of geometry in designing the products or Dymaxion House and Geodesic domes to invent a new mapping system based upon the same technology or system of geometry.

Leonardo wrote a treatise on painting in which he described the summits of mountains seen through different densities of air, based upon URB 233V. In this he stated, ". .. mountains ... when you make one more distant than another make the bases increasingly light, and when they are raised up higher show more of their true form and colour." " Leonardo's maps of the Arno and Mugnone rivers demonstrated this concept in painting and drawing form. Leonardo the artist used the skills of visual science to describe both machinery for dredging canals and for drawing beautiful maps that indicated the mountains, valleys and relief of the area he lived in Italy around Florence. Thus Leonardo predated Fuller in his ability to understand and analyze circular and linear geometry through visual science or perception in his creation of new inventions. The basic artisan skills that Leonardo gained under the instruction of Verrocchio in his studio allowed Leonardo to extend the realm of science through the visualization of art. Leonardo's artistic skills preceded his scientific discoveries. Concept formation is a perceptual, right brain or holistic act of the imagination.

Fuller described both the function of Science and the Function of Design in his book Ideas and Integrities. He stated about the function of science that

Typical of our working definitions as applied to science is: the function of science is to prospect for total society by taking the universe apart; that is resolve it into primary factors and elements by progressive isolation and subsequently to obtain precise measurements of the behavior characteristics of the isolated events or components. ${ }^{8}$

By this he meant that science is primarily about analysis and not synthesis. The function of science is exclusion and not inclusion. That the ability of present science to put together the world it has taken apart was futile in principle. Secondly he stated about the function of design, ". . . design puts together combinations of special behavior elements to arrive at special advantages for the special 'process' man. It is through design that man has evolved to his present extended manipulation of environment. The functioning of design is comprehensive." 9

Thus Fuller described the two basic assumptions of science and design and their opposite approaches to problem solving. Leonardo da Vinci and R. Buckminster Fuller both analyzed the basic geometrical components of nature and extended these findings into inventions or designs. Fuller described design as the point where man sticks his neck out or innovates.

Historically Leonardo experimented with flying machines. Often times these machines attempted to row through air. Leonardo did several experiments and drawings with these types of machines. Often they failed. From the very failures of these products, Leonardo constructed again. Fuller's Dymaxion Tubular Rowing Shell in 1947 paralleled the invention of Leonardo's attempts to row through air. The tensegrity structures that Fuller designed were directly related in concept to the shell and tension structure of his rowing machines. These structures and machines represented man's ability to extend the manipulation of his 
environment through machines that replicated his own skeleton and tensile system.

The ability to stick one's neck out and innovate is directly related to Sheldon's measurement of thinking aggression. The scientist is by his nature dedicated to thinking, but it is a very inhibited and analytical style. There is no room for error, precision means survival to a slender ectomorph. The sequential nature of science allows for no errors or gaps in judgment. It is an exclusionary process, one of harvesting minute objects versus hunting the whole.

High thinking aggression implies inclusion, it is a hunting and not a foraging process. The mesomorph may err, but he is willing to stick his neck out. The hunter travels alone, his results benefit the tribe or clan through later distribution of tools or wealth. Fuller, like Leonardo before him, traveled far in pursuit of knowledge, but the most important attribute that he had was the use of tools in the exercise of his imagination or investigation into the nature of our universe.

It is apparent that the nature of these two geniuses was very similar. It is also apparent that their explorations took them along unique but coincidental pathways in the discovery of scientific laws. Their explorations for the general welfare of society led to inventions of the by-products of their search. Leonardo stated, "The eye, which is said to be the window of the soul, is the primary means by which the sensus communis of the brain may most fully and magnificently contemplate the infinite works of nature. .."10 Again, science and engineering proceed initially from perception through the visual field. Design follows in the same manner.

Modern science continues to explore and measure existing facts of nature, but from the telescope to the microscope the human eye has been the portal to all knowledge. Fuller, like Leonardo before him, used the human eye to connect to the brain in order to create inventive models. Fuller often declared in fact that his lack of vision in his unaided eyesight as a child allowed him to see more basic shapes in nature. The ability to predict or invent the future was directly related to his ability of perception aided by the technology of his famous glasses.

\section{CONCLUSION}

While I was a student at the University of Pennsylvania both Louis I. Kahn and R. Buckminster Fuller were associated either with the Department of Architecture or Fuller's World International Research Center. Kahn delivered a lecture in which he marveled at the drawings of Leonardo da Vinci. It has become apparent over time that Louis I. Kahn was a great architect in the manner of Vitruvius, but that Leonardo and R. Buckminster Fuller were the inventive geniuses of their centuries.

These two men had the most far reaching interests of any men of their times and extended the frontiers of technology further than any others. To them rightfully extends the word genius. Architecture has been described as the invention of inventions by Lebbeus Woods, but the initial inventions of mankind before they are reassembled into architecture are the direct result of the inventive genius. Not the scientist who analyzes components, nor the engineer who tests inventions once conceived, but the artisan originator whose total perception, thinking and action are focused upon the actual or real object at hand. Architecture is the recombination of all inventions into a sum product of research, artistic conceptions and tested engineering principles. But design will always have at its origin the understanding of nature and the ability to take a risk in order to extend man's comprehensive domination of his domain, the universe.

\section{NOTES}

' Kemp, M., Leonardo da Vinci, The Marvellous Works of Nature and Man, Yale University Press, London, UK, 1988, p. 245.

2 Ibid., p. 252.

${ }^{3}$ Fuller, R. Buckminster, Ideas and Integrities, Collier Books, New York, NY, 1963, p. 112.

4 Taylor, P., The Notebooks of Leonardo Da Vinci, New American Library, New York, NY, 1960, p. xiii.

${ }^{5}$ Ibid., p. xiv.

${ }^{6}$ Kemp, op. cit., p. 120.

${ }^{7}$ Kemp, op. cit., p. 84.

${ }^{8}$ Fuller, op. cit., pp. 188-189.

${ }^{9}$ Fuller, op. cit., p. 189.

${ }^{10}$ Kemp, op. cit, p. 245.

\section{Photographs}

1 Stacking Patterns, R. Buckminster Fuller. Cosmography, p. 164.

2 Lune Studies, Leonardo da Vinci. Leonardo Da Vinci, Artabras Book, p. 406.

3 Geoscope, R. Buckminster Fuller. Ideas and Integrities, p. 192.

4 Arch Studies, Leonardo da Vinci. Leonardo Da Vinci, Artabras Book, p. 263.

5 Dymaxion 4-D House, Chicago, R. Buckminster Fuller. Ideas and Integrities, p. 192.

6 Helicopter, Leonardo da Vinci. The Notebooks of Leonardo Da Vinci, Pamela Taylor, p. 128.

7 Richard Buckminster Fuller. Intuitions, cover.

8 Self Portrait, Leonardo da Vinci, Leonardo Da Vinci, Artabras Book, p. 13. 